\title{
Analysis of the influence of phase supply angular range on the parameters of a switched reluctance motor
}

\author{
Barttomiej Adamski and Krzysztof Wrobel* \\ Faculty of Electrical Engineering, Automatic Control and Computer Science, Opole University of Technology, Poland
}

\begin{abstract}
The paper presents the results of studies on the impact of the angular range of phase supply on the parameters of a drive based on a switched reluctance motor. The studies were carried out for a drive with a three-phase motor supplied from a modified power supply system, enabling changes in the phase winding configuration. The paper presents the results obtained on the basis of calculations in a simulation model of the drive in the Matlab/Simulink environment for serial and parallel winding configurations.
\end{abstract}

\section{Introduction}

Switched reluctance motors (SRMs) require electronic supply and control systems in order to function [1-5]. A typical supply system for SRMs is an asymmetrical Hbridge (half-bridge). In drives powered from typical supply systems, electromagnetic torque decreases relatively quickly with increasing rotational speed. This is the result of shortening the time of current flow through the windings in phase supply cycles, which reduces their average value.

Methods of counteracting this phenomenon include increasing the voltage value of the power source and the use of special power converters. The use of a highervoltage source accelerates the processes of rising and falling currents in the SRM phase windings. In this connection, the average current in the phase windings and the value of electromagnetic torque increase, enabling extension of the speed range and acquisition of greater drive power. However, this solution has its disadvantages. The use of a higher-voltage source may increase costs, reduce the efficiency of the inverter, or prove impossible to implement. Moreover, this solution causes increased commutation losses in the low speed range.

An alternative to higher-voltage sources is the use of modified supply systems, one of which enables multiple reconfigurations of the SRM windings during phase supply. Changes can be made in the configuration of winding connections without interrupting the flow of current. In the low speed range, the motor can work with windings connected in series, in the high speed range with windings connected in parallel. This enables the reduction of commutation losses; however, due to the additional elements in the serial configuration, the losses in the conduction states increase. To determine the mechanical characteristics and efficiency of this system, it is first necessary to determine the dependence of commutation angles on the rotational speed.

\section{Modified SRM converter}

The modified SRM power supply system (Fig. 1) used here consists of two asymmetrical H-bridges and a circuit connecting them, consisting of a transistor T5 and a diode D5, enabling connection of the winding coils in series via transistors $\mathrm{T} 4, \mathrm{~T} 5$, and $\mathrm{T} 1$ or in parallel via transistors $\mathrm{T} 1, \mathrm{~T} 2, \mathrm{~T} 3$, and $\mathrm{T} 4$. The energy return occurs in a parallel configuration when all transistors are turned off, and in a serial configuration when only transistor T5 is switched on. This solution enables the SRM to be supplied in all modes occurring in a typical power system with coils connected in series configuration and in additional modes, extending the drive's operating range. Additional operating states include parallel supply of the SRM windings and parallel return of energy to the power source. The disadvantage of the system is an increase in conductive losses when the system is operating with coils in serial configuration. In this configuration, however, the system generally works in the low speed range, reducing the commutation losses relative to the parallel configuration.

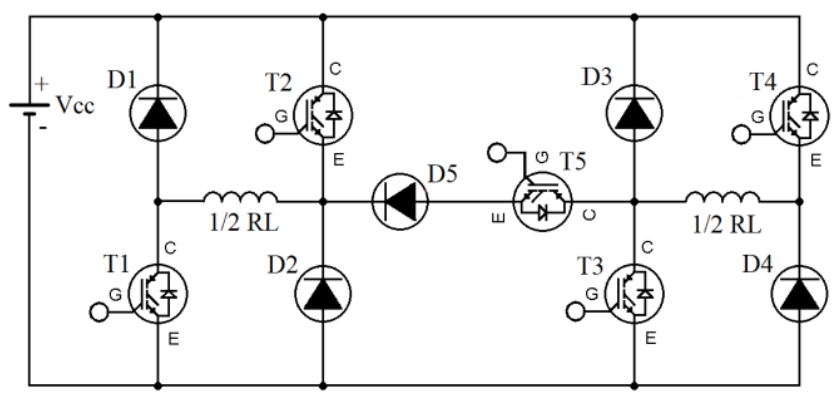

Fig. 1. One channel of a SRM converter enabling the winding configuration.

The drive simulation model was developed in the Matlab/Simulink environment. The model uses the measurement characteristics of the motor, which were implemented in the form of arrays containing the phase

\footnotetext{
Corresponding author: k.wrobel@po.edu.pl
} 
current dependence on magnetic flux and rotor position angle as well as electromagnetic torque values as a function of the phase current and rotor position angle. The model was developed for a three-phase motor with a nominal power of $750 \mathrm{~W}$ at $3000 \mathrm{rpm}$ supplied from a $230 \mathrm{~V}$ converter. During the simulation, the switch-off angle $\left(\alpha_{\text {off }}\right)$ for a given speed was constant. The values of the phase currents were limited to $8 \mathrm{~A}$.

\section{Results}

Drive operation simulations were performed for different rotational speeds and two system operation modes, i.e., for power supply and energy return in serial (S) and parallel (P) configurations. Fig. 2 shows the relationship between the maximum torque values and the corresponding efficiency values vs. rotational speed for both modes. The switch-off angle $\left(\alpha_{\text {off }}\right)$ had been set earlier, assuming that the value of the phase-supplying angle $\left(\alpha_{\mathrm{s}}\right)$ was $30^{\circ}$. The previously determined $\alpha_{\text {off }}$ values are presented in Table 1.

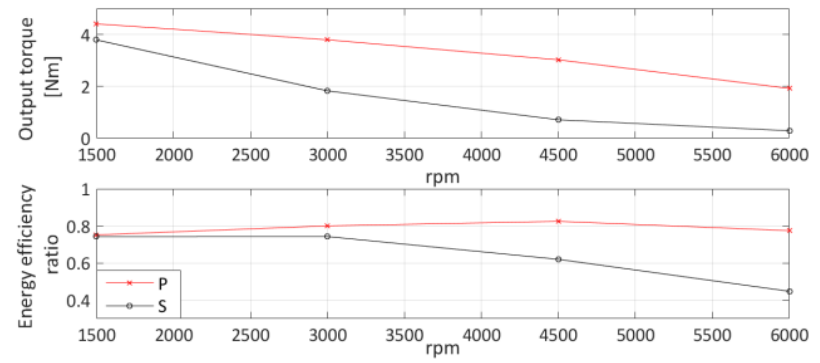

Fig. 2. Maximum output torque and drive efficiency vs. rotational speed in series and parallel configurations.

Table 1. Applied values of the switch-off angle $\alpha_{\text {off }}$ for serial and parallel configuration at different speeds.

\begin{tabular}{|c|c|c|c|}
\hline \multicolumn{2}{|c|}{ Serial configuration } & \multicolumn{2}{c|}{ Parallel configuration } \\
\hline$\alpha_{\text {off }}$ & $\mathrm{rpm}$ & $\alpha_{\text {off }}$ & $\mathrm{rpm}$ \\
\hline-14 & 1500 & -9 & 1500 \\
\hline-27 & 3000 & -14 & 3000 \\
\hline-30 & 4500 & -21 & 4500 \\
\hline-31 & 6000 & -27 & 6000 \\
\hline
\end{tabular}

The next set of figures shows the influence of the phase supply range on the characteristics of the SRM for the values of $\alpha_{\text {off }}$ from Table 1. Figs. 3 and 4 show the dependences of torque and power supplied from the power supply vs. the value of phase-supplying angle $\alpha_{\text {s }}$ for the serial configuration. Figs. 5 and 6 show similar relationships for the drive working in the parallel configuration.

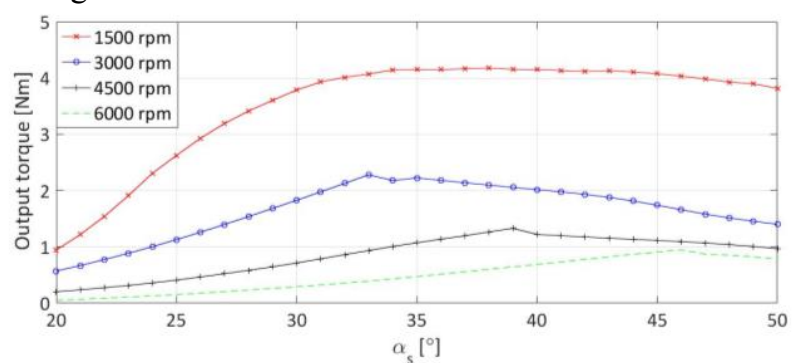

Fig. 3. Output torque vs. phase supply ranges at different rotational speeds in the serial configuration (S).

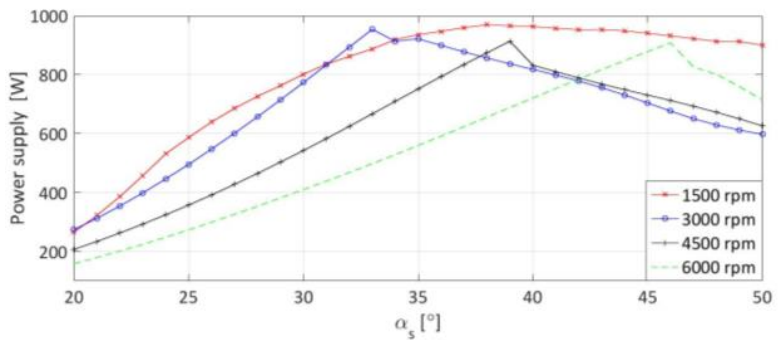

Fig. 4. Power supply vs. phase supply ranges $\alpha_{\mathrm{s}}$ at different rotational speeds in the serial configuration $(\mathrm{S})$.

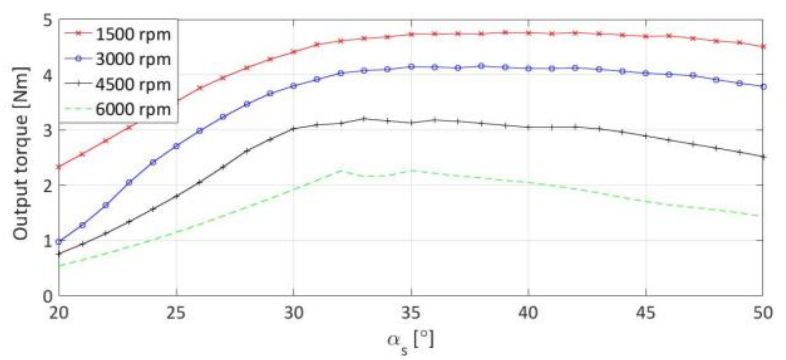

Fig. 5. Output torque vs. phase supply ranges at different rotational speeds in the parallel configuration $(\mathrm{P})$.

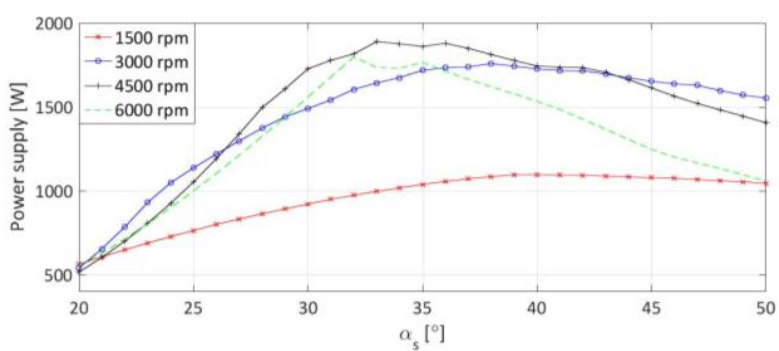

Fig. 6. Power supply vs. phase supply ranges $\alpha_{\mathrm{s}}$ at different rotational speeds in the parallel configuration $(\mathrm{P})$.

\section{Conclusions}

The results presented here were obtained for a threephase switched reluctance motor model. The influence of the phase supply range on system operation was analyzed. In the calculation of the dependence for different rotational speeds, constant values of supply voltage and switch-off angle were assumed.

At a speed of $1500 \mathrm{rpm}$, the shape of the obtained dependences differs from the others; this is influenced by the operation of the system in the current limiting mode.

\section{References}

1. M. Yaich, M. Ghariani, Journal of Electrical Systems, 14, Issue: 1, 156-173 (2018)

2. M. Korkosz, B. Pakla, (i-MITEL), Sulecin, , pp. 1-4, (2018), 10.1109/IMITEL.2018.8370473

3. A. P. Khedkar, P. S. Swami, Intern. Conference on Computation of Power, Energy Information and Communication, Melmaruvathur, 522-526, (2017)

4. P. Wach, K. Tomczewski, Electrical Engineering 85, 275-281, Springer-Verlag, (2003)

5. Q. Sun, J. Wu, C. Gan, J. Guo, IEEE Trans. on Power Electronics, 34, 3, 2622-2634, March (2019) 